This is the final peer-reviewed accepted manuscript of:

Stola, F., Ravaglioli, V., Silvagni, G., Ponti, F. et al., "Injection Pattern Investigation for Gasoline Partially Premixed Combustion Analysis," SAE Technical Paper 201924-0112, 2019

The final published version is available online at:

https://doi.org/10.4271/2019-24-0112

Rights / License:

The terms and conditions for the reuse of this version of the manuscript are specified in the publishing policy. For all terms of use and more information see the publisher's website.

This item was downloaded from IRIS Università di Bologna (https://cris.unibo.it/)

When citing, please refer to the published version. 


\title{
Injection Pattern Investigation for Gasoline Partially Premixed Combustion Analysis
}

\author{
Author, co-author (Do NOT enter this information. It will be pulled from participant tab in \\ MyTechZone) \\ Affiliation (Do NOT enter this information. It will be pulled from participant tab in MyTechZone)
}

\begin{abstract}
Nowadays, compression-ignited engines are considered the most efficient and reliable technology for automotive applications. However, mainly due to the current emission regulations, that require increasingly stringent reductions of NOx and particulate matter, the use of diesel-like fuels is becoming a critical issue. For this reason, a large amount of research and experimentation is being carried out to investigate innovative combustion techniques suitable to simultaneously mitigate the production of NOx and soot, while improving engine efficiency.

In this scenario, the combined use of compression-ignited engines and gasoline-like fuels proved to be very promising, especially in case the fuel is directly-injected in the combustion chamber at high pressure. The presented study analyzes the combustion process produced by the direct injection of small amounts of gasoline in a compression-ignited light-duty engine. The engine under investigation has been modified to guarantee a stable engine operation over its whole operating range, that is achieved controlling boost pressure and temperature, together with the design of the injection pattern.

Experimental tests have been performed to highlight the impact of several control variables on the combustion effectiveness, i.e. on combustion efficiency and ignition delay. To identify the main mechanisms which impact the start of the combustion process and the sensitivity to the variation of the main control parameters, several tests have been run, directly-injecting constant amounts of gasoline in a compression ignited engine. These tests have been performed changing intake pressure and temperature (when suitable to maintain combustion stability), fuel pressure and injection timing within the cycle.
\end{abstract}

\section{Introduction}

Nowadays, road transportation is still mainly based on the use of internal combustion engines (ICE); therefore the increase of engine efficiency and the reduction of pollutant and greenhouse emissions are of fundamental importance to minimize its environmental and health impact. High levels of efficiency can be achieved through compression-ignited (CI) engines, which are currently the most efficient and reliable engine technology used in automotive applications. However, CI engines are usually powered by the highpressure direct-injection of Diesel, which leads to a combustion process that is heterogeneous by nature. Such combustion process is characterized by the simultaneous production of a significant amount of particulate matter and NOx [1,2], both severely limited by current emission regulations.

To overcome the mentioned problems, a large amount of research has been carried out over the past years to investigate innovative combustion techniques characterized by high efficiency and low emissions. These combustion strategies, termed low temperature combustions (LTC), are usually characterized by high ignition delays (which guarantee a more homogeneous air-fuel mixing) and by the lean combustion of a mixture of air and gasoline-like fuels [3-5]. These combustion methodologies proved to be effective to simultaneously reduce engine-out emissions and improve efficiency [6-9].

The main challenge, which limits the use of LTC strategies, is the control of combustion phasing $[10,11]$. The fundamental form of LTC strategy, homogeneous charge compression ignition (HCCI), occurs when a fully premixed air-fuel mixture is compressed to the point of auto-ignition by the piston, with chemical kinetics controlling the start of combustion (SOC). Since SOC is controlled by chemical kinetics, it is very sensitive to slight variations of the incylinder thermal conditions. As a result, predicting the start of combustion is very difficult, as well as keeping the combustion process between the allowable limits for misfire and knocking [12$14]$.

One promising technique to overcome the problems of $\mathrm{HCCI}$ combustion is the gasoline partially premixed combustion (PPC), usually combined with the use of multiple direct injections to properly design the shape of the heat released during the combustion process. In this combustion process, the first injection ignites as an HCCI combustion (SOC strongly dependent on cylinder thermal conditions) and increases pressure and temperature inside the combustion chamber, the goal being to reduce the ignition delay of the following injections [15]. The reduction of the ignition delay makes the control of combustion phasing easier, because combustion location is less affected by cylinder thermal conditions and more correlated to the injection timing.

Although combustion control of PPC combustions becomes more robust (compared to HCCI operation), the optimization of the whole injection pattern is still very complicated, because slight variations of the injection parameters (such as start and duration of the injections, together with the injection pressure) can strongly affect the

Page 1 of 8 
effectiveness of the combustion process. In particular, the combustion of the first injection, which is strongly influenced by in-cylinder thermal conditions, still plays an important role, because it defines pressure and temperature at which the fuel mass introduced during the second injection will auto-ignite. As a result, a poor or inefficient combustion of the fuel introduced with the first injection will lead to a long ignition delay of the mass of fuel introduced during the second injection and consequently to a retarded center of combustion.

This paper presents the first step of a work aimed at the optimization of PPC combustion in a compression-ignited engine, fueled with gasoline. The main objective of the activity is to investigate the fundamental aspects of this LTC, to understand how the variation of the engine control parameters affects the combustion of small amounts of gasoline injected. As a matter of fact, the robust control of a multiple-injection pattern can be achieved only if the mechanisms that influence the auto-ignition of the first injection (i.e. the one with the longest ignition delay) have been properly characterized. As discussed in literature [16-18], the control parameters that mainly influence the performance of gasoline PPC combustion are the intake conditions (pressure and temperature) and the injection pressure. This paper describes how the 4-cylinder Common-Rail Diesel engine under investigation has been modified to investigate the effects of the mentioned parameters on the ignition mechanisms of a small mass of gasoline (similar to the one that could be introduced in the first injection of a multiple pattern). In the proposed layout, a specifically designed fuel system has been added, properly managed to provide high-pressure gasoline to only one cylinder. This cylinder has been used to analyze gasoline autoignition, while the other 3 cylinders (still fueled with Diesel) have been used to keep the engine at the proper engine speed and to vary the boost pressure, changing the turbine upstream pressure. Several experimental tests have been carried out to highlight the effects of intake pressure, intake temperature and gasoline injection pressure variations on combustion efficiency and ignition delay.

\section{Experimental setup}

The complete study presented in this work has been performed running a $1.3 \mathrm{~L}$ compression-ignited engine installed in a test cell. The standard layout consisted in a turbocharged Diesel engine, equipped with a Common-Rail Multi-Jet injection system (designed to operate at injection pressures up to 1600 bar), mainly characterized by a highpressure volumetric pump, the fuel rail and 4 solenoid injectors, directly connected to the rail. The main technical characteristics of the engine under investigation are summarized in Table 1.

Table 1. Engine technical characteristics.

\begin{tabular}{|l|l|}
\hline Displaced volume & $1248 \mathrm{cc}$ \\
\hline Maximum Torque & $200 \mathrm{Nm} @ 1500 \mathrm{rpm}$ \\
\hline Maximum Power & $70 \mathrm{~kW} @ 3800 \mathrm{rpm}$ \\
\hline Injection System & Common Rail, Multi-Jet \\
\hline Bore & $69.6 \mathrm{~mm}$ \\
\hline Stroke & $82 \mathrm{~mm}$ \\
\hline Compression ratio & $16.8: 1$ \\
\hline Number of Valves & 4 per cylinder \\
\hline Architecture & L4 \\
\hline Firing Order & $1-3-4-2$ \\
\hline
\end{tabular}

To start investigating the auto-ignition of gasoline, the injection system has been modified adding a new high-pressure system for gasoline. The additional fuel system consists of another high-pressure pump, kept in motion by the engine crankshaft, and another rail. The additional rail provides commercial gasoline ( $95 \mathrm{RON})$ to one of the 4 injectors (cylinder 1), while the other 3 injectors are fueled by the standard injection system. With regard to the injectors, gasoline injection is performed using the same solenoid injector present in the standard engine layout. The installation of the new injection system is reported in Figure 1.

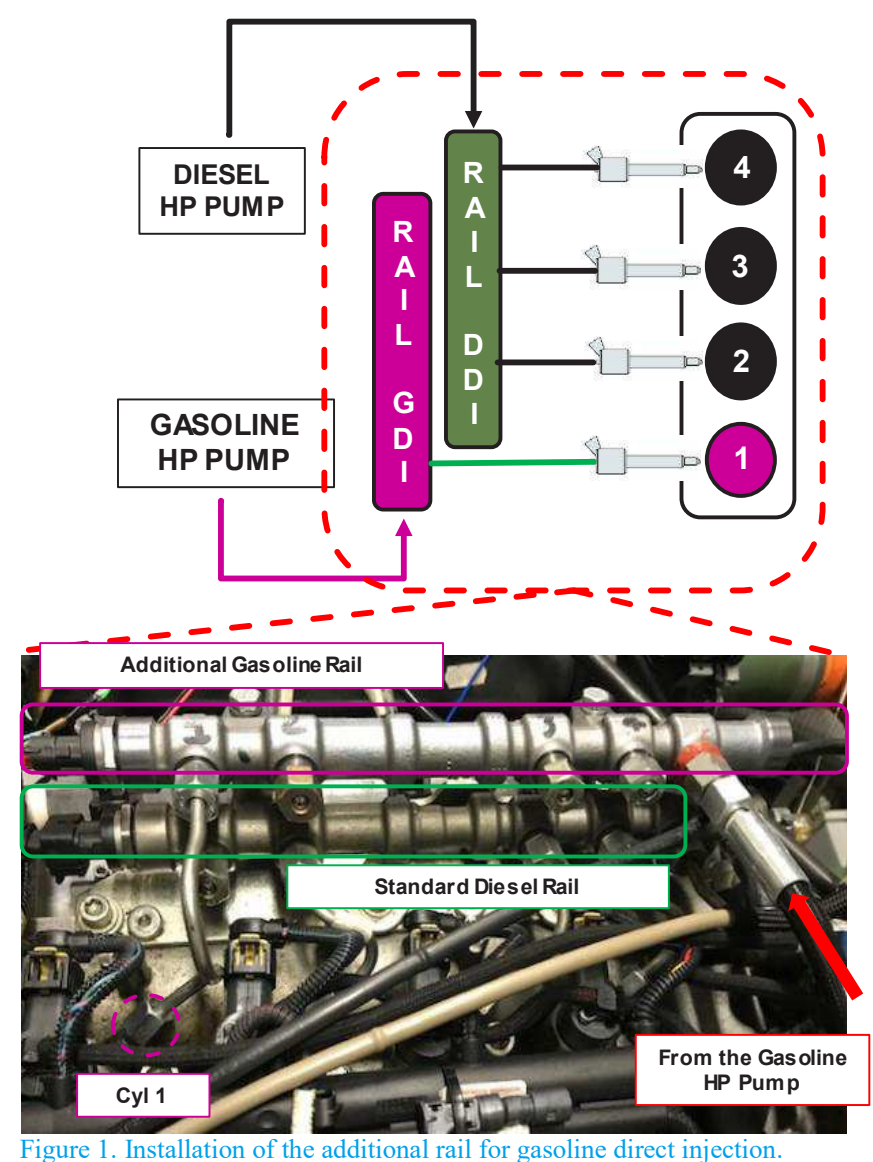

Once the fuel system has been modified installing the high-pressure gasoline injection system, the injection controller has been implemented in a specifically designed Rapid Control Prototyping (RCP) system, based on a National Instruments cRio 9082. The RCP system controls both fuel pressure and injection timing. Fuel pressure is simply controlled varying the duty of the PWM command for a solenoid flow metering valve (the selected duty depends on the difference between target and measured fuel pressure). To manage injection timing, the RCP samples at high frequency the signal coming from the crankshaft speed sensor (optical encoder that produces 180-2 pulses per rotation), which allows the system to determine the instantaneous angular location within the engine cycle. Once the angular position has been determined, the RCP outputs the logical commands for the Common-Rail injector, i.e. Start of Injection (SOI) and Energizing Time (ET), that are communicated to the standard ECU for engine control via CAN bus. Finally, the standard ECU converts the logical commands and generates the corresponding electric commands for the high-pressure injector of cylinder 1. 
The RCP system is also suitable to manage Diesel injection in the other 3 cylinders. To do so, it communicates with the standard ECU via CAN bus to read and overwrite (when necessary) the injection parameters of interest, i.e. Diesel Energizing Time (DET) and Diesel Start of Injection (DSOI). The real-time control of Diesel injection is also necessary to guarantee the proper boost pressure to cylinder 1 . As a matter of fact, the load of the 3 cylinders fueled with Diesel and the position of the actuator that controls the mass flow through the turbine (variable geometry turbine, VGT) are real-time adjusted by the RCP to keep boost pressure at its target value.

During engine testing, all the signals coming from the standard sensors (already present on-board for control purposes) can be monitored and acquired using INCA software and ETAS hardware. In addition, in-cylinder pressure signals have been acquired installing one pressure sensor (AVL GH14P) per cylinder. Cylinder pressure is sampled and analyzed using an indicating system (OBI by Alma Automotive) that performs in-cylinder pressure pegging (using the boost pressure measurement, set equal to the cylinder pressure measurement in a proper angular window of the intake stroke) and real-time calculates all the main combustion indexes, such as CA50, indicated torque and pressure peak. Figure 2 reports a scheme of the whole layout used to investigate gasoline PPC combustion.

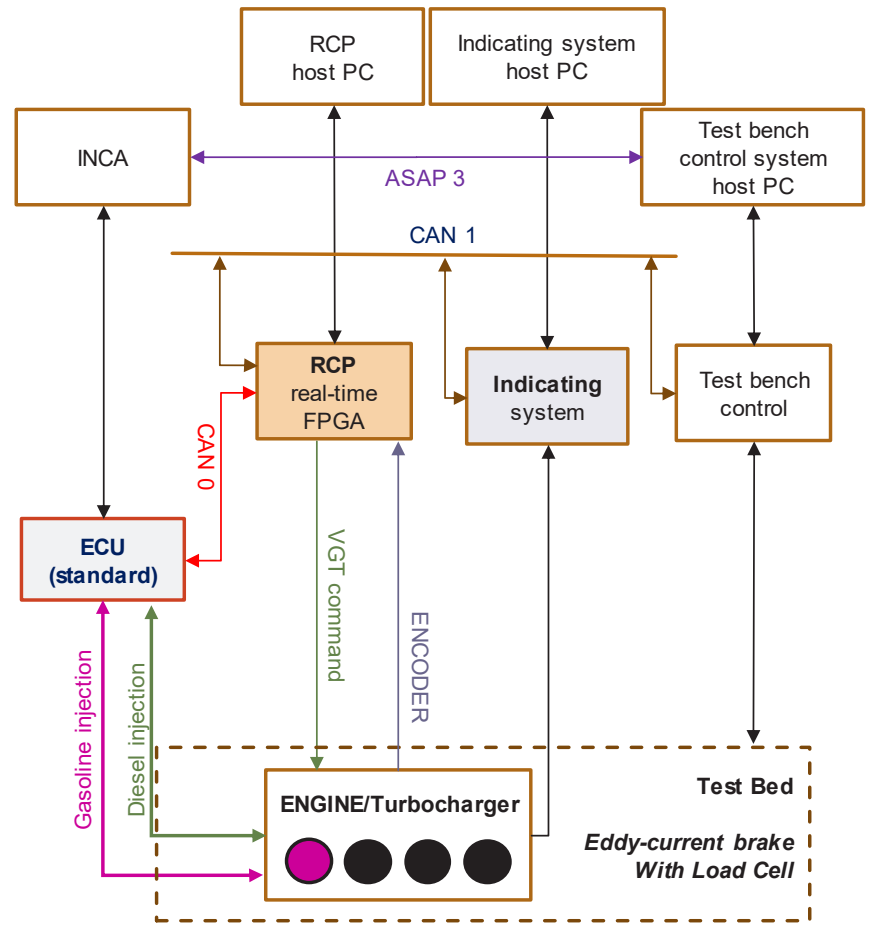

Figure 2. Scheme of the experimental setup used to investigate gasoline PPC combustion.

The above discussed setup has been used to investigate the main sensitivities of gasoline auto-ignition to the variation of several control parameters, such as intake temperature, intake pressure and fuel pressure.

\section{Combustion investigation}

As above mentioned, this paper reports the first part of a study aimed at the optimization of gasoline PPC combustion in a compression ignited engine. As already discussed, all the LTC strategies are characterized by a high sensitivity to slight variations of the inPage 3 of 8 cylinder thermal conditions, which result in an extremely difficult control of the combustion phasing within the cycle. As a matter of fact, the variations of in-cylinder thermal conditions affect the ignition delay of the mixture, especially when high ignition delays are used (early injection). To optimize combustion efficiency and stability, it is therefore necessary to identify how the variations of the main engine control parameters affect the ignition delay of the fuel.

With the prospect of setting up a model suitable to predict the ignition delay of the mixture in open-loop, the experimental analysis has been focused on the behavior of small quantities of injected fuel, i.e. the ones typically used for Pilot injections. The analysis has been limited to single injections (instead of complete patterns) to avoid interactions between the fuel amounts introduced during different injections. As an example, in a 2-injection pattern, the mass introduced during the Main injection might burn together with the mass injected during the Pilot or changes its ignition delay, because of the heat received during the vaporization stage. In this study, the ignitions of 2 different injected amounts of gasoline have been investigated:

- $2 \mathrm{mg} / \mathrm{stroke}$;

- $4 \mathrm{mg} / \mathrm{stroke}$.

For each amount of fuel, 3 different levels of fuel pressure have been tested, i.e.:

- 300 bar;

- 500 bar;

- 700 bar.

Since the injectors used in this study are the standard solenoid injectors calibrated for Diesel injection, the amount of fuel injected has been verified using a high accuracy flow meter (FlowSonic LF), characterized by a measurement range compatible with the small mass flow rates introduced inside cylinder 1 (the only cylinder in which gasoline is injected).

For each combination of fuel mass and injection pressure, several steady-state tests have been run changing the SOI from 50 to $10 \mathrm{deg}$ BTDC. The same sequence has been repeated for 2 levels of intake temperatures $\left(30\right.$ and $75^{\circ} \mathrm{C}$, controlled through an air cooler installed in the middle between the compressor and the intake manifold) and 2 levels of boost pressure (1450 mbar and 1550 mbar, the closed-loop control is managed by the RCP system, which changes the position of the VGT actuator). The minimum boost pressure target (1450 mbar) has been identified experimentally as the minimum value that guarantees a reliable auto-ignition of the injected amount of gasoline in all the investigated temperature and SOI conditions [19]. Starting from that value, another slightly higher target (100 mbar higher) has been tested to verify the effects on combustion stability in case a margin with respect to the combustion stability limit is provided.

The whole amount of experimental tests has been analyzed to highlight the sensitivities of the auto-ignition mechanism with respect to the variation of the discussed control parameters. The attention has been focused on how such variations affect the way energy is released during the combustion process and the ignition delay. 


\section{Analysis of the Heat Release}

The analysis of the heat release is usually based on the calculation of the apparent rate of heat released (ROHR), that can be directly calculated from cylinder pressure measurement through Eq. (1) [20]. Here, $p$ and $V$ are in-cylinder pressure and volume (respectively), $\theta$ is the crankshaft angle and $\gamma$ is the specific heat ratio (kept constant at 1.32 in this work).

$$
R O H R=\frac{1}{\gamma-1} \cdot V \cdot \frac{d p}{d \theta}+\frac{\gamma}{\gamma-1} \cdot p \cdot \frac{d V}{d \theta}
$$

Such heat release is a net heat release, in which the losses due to heat transfers through the walls and blow-by are included (negative contributions). However, the amount of energy, released during the combustions of the small amounts of fuels considered, is usually comparable to the energy exchanged through the walls or the crevices (especially when $2 \mathrm{mg} /$ stroke are injected). To highlight the effect of the combustion process, a specific methodology for the estimation of the total amount of energy released only during the combustion process (i.e. compensating heat transfers through the walls and blowby) has been set up.

\section{Calculation of the Gross Heat Release}

In-cylinder pressure measurement can be easily used to calculate an estimation of the net heat released during combustion through Eq. (1). As already mentioned, the net release doesn't capture the energy flows through cylinder walls and crevices, that result in a negative contribution to the apparent heat release. If the amount of (positive) energy released during the combustion process is comparable to the discussed negative contribution, it might be difficult to perform detailed studies of the ignition process, because some of the phenomena of interest (such as the vaporization of the injected fuel) might be hidden by the losses.

To optimize the investigation of the combustion process, the heat release calculated through Eq. (1) (calculated from the pressure signal acquired during a generic test) has been compensated removing the heat release trace calculated during a motored test (no fuel injection) run in the same conditions of intake pressure, intake temperature and rotational speed.

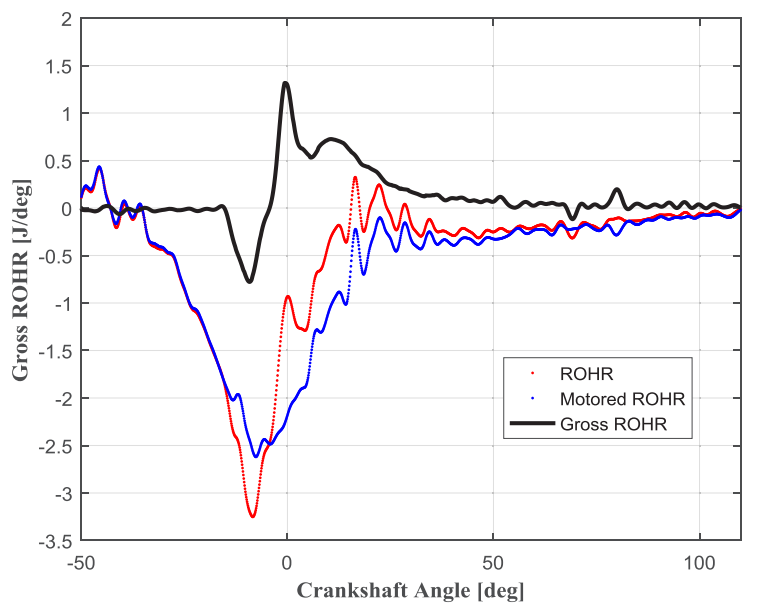

Figure 3. Gross ROHR calculation for a test run at $2000 \mathrm{rpm}$, boost pressure equal to $1550 \mathrm{mbar}$, intake temperature equal to $75^{\circ} \mathrm{C}$ and $\mathrm{pRail}=300 \mathrm{bar}(4$ $\mathrm{mg} /$ stroke).

Page 4 of 8
As a matter of fact, even though injection is deactivated in cylinder 1, the boost pressure can still be controlled in closed-loop using the other 3 cylinders (fueled with Diesel). As reported in Figure 3, this procedure allows accurately compensating the effects of the losses, obtaining an estimation of the gross ROHR. This quantity is characterized by 2 interesting regions: a negative part, corresponding to the vaporization of the fuel (during the vaporization stage the fuel receives heat), and a positive part, i.e. the combustion process (during the combustion stage the fuel releases heat).

To properly compensate the effects of the losses, one specific motored test has been run for each value of boost pressure and intake temperature analyzed in this work (after each fired test). Given the amount of fuel injected ( 2 or $4 \mathrm{mg} /$ stroke), the use of the calculated gross release is fundamental to properly analyze the effects of injection pressure and SOI variation on the vaporization and combustion stage.

\section{Heat Release Comparison}

Once the gross heat release has been calculated (as described in the above section) for all the tests under investigation, it has been analyzed to highlight the effects due to the variation of the control parameters.

The first aspect to be noticed is that SOI variation has a significant impact on the efficiency of the gross heat release (total energy released during the combustion process with respect to the energy introduced with the fuel). As it can be observed in Figure 4, which reports the result of the SOI scan performed injecting $4 \mathrm{mg} / \mathrm{stroke}$, keeping boost pressure at $1550 \mathrm{mbar}$, intake temperature at $75^{\circ} \mathrm{C}$ and rail pressure at $300 \mathrm{bar}$, both vaporization and combustion are significantly influenced. In particular, the speed of the vaporization process is significantly faster when the injection is retarded and becomes slower when the injection is advanced before the TDC. This behavior is obviously due to the different in-cylinder temperature experienced by the amount of fuel, when injected in different positions during the compression stroke.

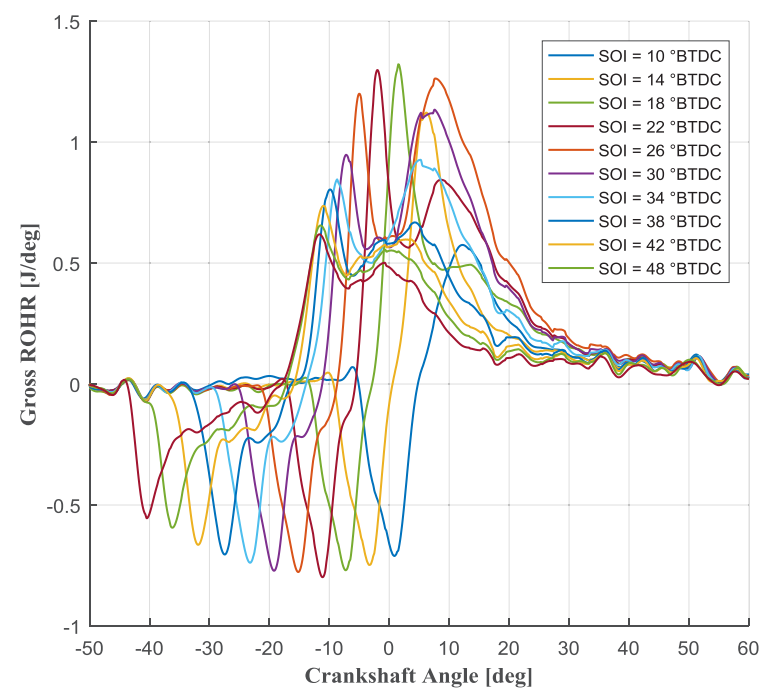

Figure 4. Gross ROHR variation during a SOI sweep (4 mg/stroke, boost pressure at $1550 \mathrm{mbar}$, intake temperature at $75^{\circ} \mathrm{C}$ and rail pressure at 300 bar) 
The maximum value of ROHR is located at an intermediate value of SOI, which is the one at which the combustion process shows its maximum impulsiveness, i.e. its maximum combustion speed. As a result, the efficiency of the combustion process is significantly influenced by the injection timing. Figure 5 reports, for the same tests shown in Figure 4, the maximum value of the cumulated heat release (CHR, i.e. the integral of the positive ROHR). This quantity shows its maximum value when the given amount of injected fuel $(4 \mathrm{mg} /$ stroke in this case) is burned with the maximum efficiency.

Figure 5 also reports the maximum of the CHR for 2 SOI sweeps run reducing boost pressure (from 1550 to 1450 mbar) and intake temperature (from 75 to $20^{\circ} \mathrm{C}$ ) respectively. It is interesting to observe that both reductions affect the total efficiency of the combustion process with respect to the first sweep, and the efficiency reduction is remarkable in the SOI range characterized by the maximum combustion efficiency (from 20 to $35 \mathrm{deg}$ ).

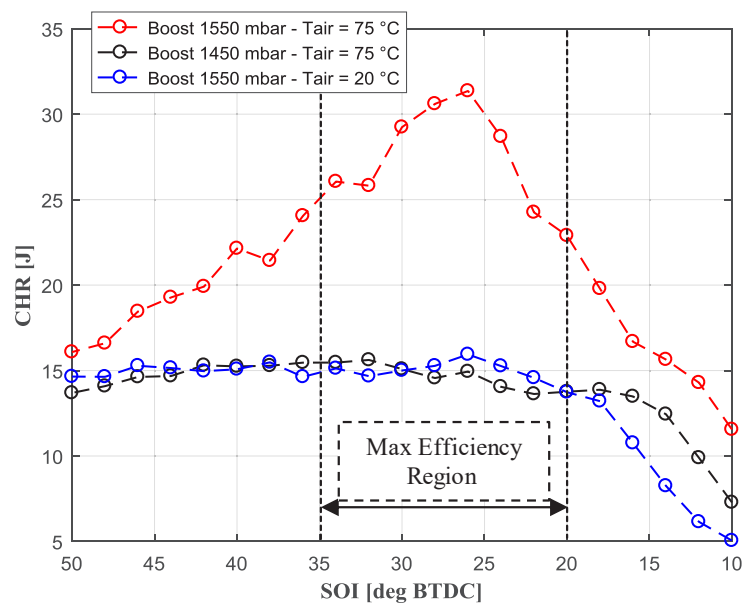

Figure 5. Comparison between the maximum values of the CHR for 3 SOI sweeps run injecting $4 \mathrm{mg} /$ stroke at 300 bar and changing the intake conditions (intake pressure and temperature).

In this range, the first SOI sweep (boost pressure $1550 \mathrm{mbar}$ and intake temperature $75^{\circ} \mathrm{C}$ ) shows the maximum efficiency when SOI is equal to $26 \mathrm{deg}$ and rapidly drops when the start of injection is changed. On the contrary, in the same SOI range the maximum CHR of the other sweep is nearly constant and stands around $15 \mathrm{~J}$. The reason of this behavior can be found in the ROHR comparison shown in Figure 6, that reports the ROHR measured during the three analyzed sweeps when a SOI equal to $26 \mathrm{deg}$ is applied.

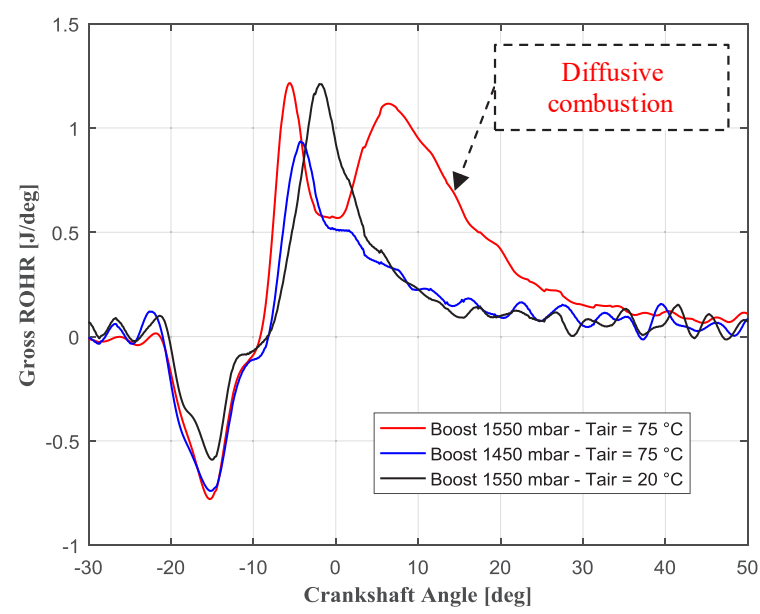

Figure 6. Comparison between the ROHR waveforms of 3 tests run at SOI equal $26 \mathrm{deg}$ BTDC, all run injecting $4 \mathrm{mg} /$ stroke at $300 \mathrm{bar}$ and changing the intake conditions (intake pressure and temperature)

When high boost pressure and intake temperature are used, the combustion process is characterized by 2 steps: a premixed combustion portion followed by a diffusive combustion. This means that the combustion process started with gasoline auto-ignition further propagates and generates the second ROHR peak. When pressure or temperature are reduced, the second ROHR peak disappears, probably because of the slower propagation of the combustion process, which stops when it reaches too lean regions of the combustion chamber (the injected fuel has more time to propagate inside the combustion chamber and therefore to reduce the local airfuel ratio before being reached by the flame). It is interesting to notice that in the SOI range characterized by the maximum combustion efficiency (from 20 to $35 \mathrm{deg}$ ) the integral of the premixed portion is not significantly affected by the variation of the control parameters; it remains nearly constant around $15 \mathrm{~J}$ for all the 3 tests.

The above analysis proves how sensitive might be the combustion of a small amount of gasoline (directly injected in a compression ignited engine) to the variation of the analyzed control parameter (SOI, boost pressure and temperature). These results also suggest that, with the perspective of a multiple injection pattern, the first injection should be performed in operating conditions that guarantee good combustion stability and efficiency, i.e. the ones in which the first pre-mixed combustion is able to further propagate within the combustion chamber. To do so, a minimum level of intake pressure and temperature needs to be guaranteed (when possible), together with the proper choice of the injection phase.

The above considerations have been verified in all the tested injection pressures, confirming that with higher injection pressure and hot temperature it is always possible to identify a SOI which maximizes the efficiency of the combustion process. The identification becomes more difficult when pressure and temperature are reduced below a certain limit (only a small premixed combustion stage is present). 


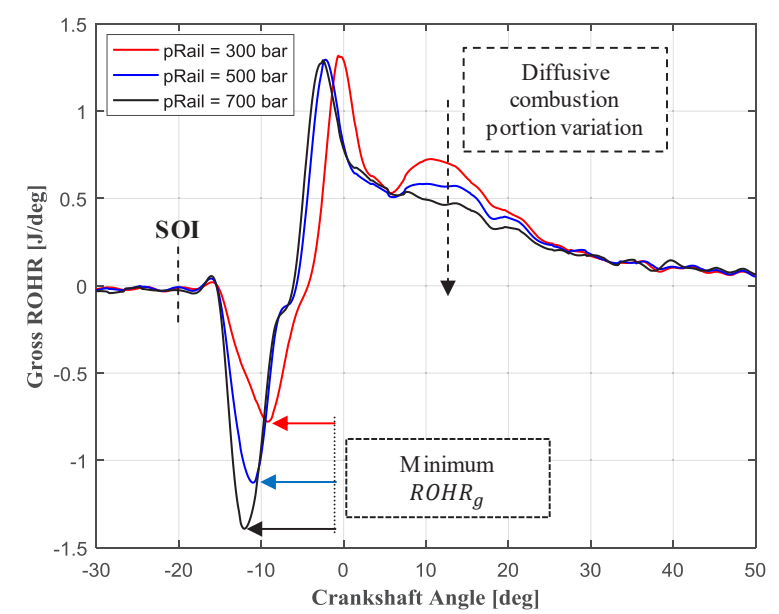

Figure 7. Comparison between the ROHR waveforms of 3 tests run at SOI equal $20 \mathrm{deg}$ BTDC, all run injecting $4 \mathrm{mg} /$ stroke and changing the fuel pressure (intake pressure and temperature kept at $1550 \mathrm{mbar}$ and $75^{\circ} \mathrm{C}$ respectively)

Comparing similar tests run at different injection pressures highlights that also the variation of this parameter has a strong impact on the measured heat release. To clarify the effects of gasoline pressure variations, Figure 7 reports a comparison between the gross ROHR calculated for 3 tests run keeping nearly identical SOI, boost pressure and intake temperature, while varying the injection pressure. The first aspect to be noticed is that increasing the injection pressure speeds up the vaporization process, which results in more negative peaks in the first portion of the gross ROHR after gasoline SOI. In addition, higher vaporization and better fuel jet penetration produce a different quality of the local air-fuel mixture. This reduces the diffusive portion, because the better air-fuel mixing accelerates the formation of ultra-lean regions in which the combustions process does not propagate.

Finally, it is easy to notice that, given a fixed injection phasing, a fuel pressure increase also speeds up the start of the combustion process, therefore reducing the ignition delay of the mixture. As already mentioned, a good prediction of the ignition delay of the mixture is necessary to properly manage combustion phasing within the cycle. Therefore, the following section reports the sensitivity of the calculated ignition delay to the variation of the control parameters.

\section{Analysis of the Ignition Delay}

The calculation of the gross heat release has been used to analyze the combustion process and determine the optimal control parameters which maximize the combustion efficiency of a small amount of fuel directly injected inside the cylinder (amount similar to the one of a Pilot in multi-jet patterns).

Another important parameter to be kept under control in LTC strategies is the ignition delay of the air-fuel mixture. This quantity, defined as the time interval between SOI and SOC, can be significantly affected by slight variations of control parameters and cylinder thermal conditions. To practically calculate the ignition delay from the gross ROHR waveforms, it has been computed as the time corresponding to the angular distance between SOI and the position in which the gross ROHR overcomes a fixed threshold, equal to $0.2 \mathrm{~J} / \mathrm{deg}$ in this study (arbitrary threshold which guarantees a robust $\mathrm{SOC}$ detection in all the analyzed tests).

Page 6 of 8
Given a set of control parameters (intake temperature, boost pressure and rail pressure) the ignition delay is mainly influenced by the injection timing, because SOI variation changes the average cylinder temperature, at which the fuel is exposed before its auto-ignition. Such average temperature is strongly influenced also by the variation of boost pressures and intake temperature, since they are responsible for different temperatures in correspondence of the gasoline SOI [19].

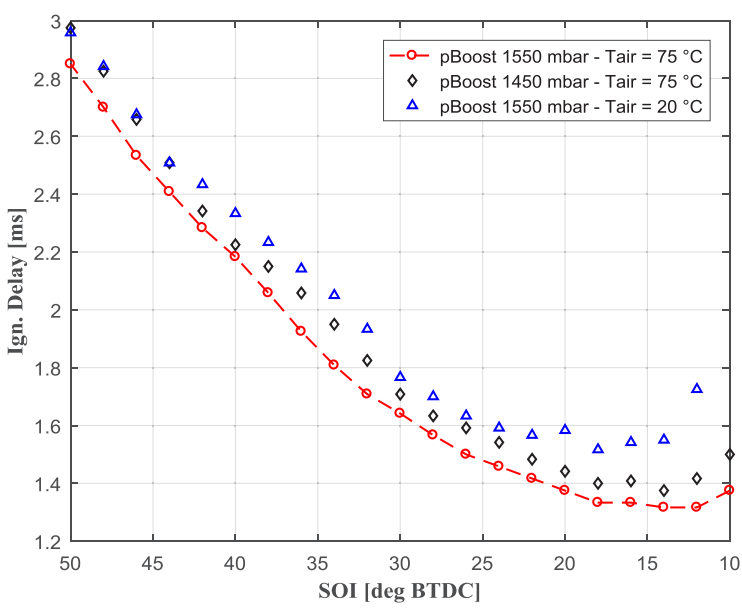

Figure 8. Comparison between the ignition delays of 3 SOI sweeps run injecting $4 \mathrm{mg} /$ stroke at 300 bar and changing the intake conditions (intake pressure and temperature)

Figure 8 provides information about the sensitivity to variations of the in-cylinder thermal conditions due to changes in the intake charge conditions (pressure and temperature). As expected, for the tests performed at pRail $=300$ bar, the minimum ignition delay is obtained in the "hottest" condition, i.e. the one in which both intake pressure and temperature are kept at the maximum value. It is interesting to notice that the measured ignition delay usually decreases when SOI is retarded, except for very retarded injections (SOI lower than $15 \mathrm{deg}$ BTDC), where the ignition delay tends to increase again. As a matter of fact, the ignition delay is not only influenced by the charge temperature in correspondence of the SOI, but by the average charge temperature in the time interval between SOI and SOC. For very retarded values of SOI, the ignition delay increases because the combustion process starts in the expansion stroke, where motored cylinder pressure and temperature are already decreasing.

Besides the thermal conditions of the air charge, the ignition delay is also influenced by the local quality of the air-fuel mixture, that is mainly determined by the amount of fuel and the pressure at which it is injected. The analysis of the gross heat release $\left(R O H R_{g}\right)$, discussed in the previous section, shows that pRail variations change the duration of the vaporization stage, which tends to be faster for higher injection pressures. Figure 9 shows that the same trend is present in the ignition delay, which tends to be smaller when the injection pressure is increased.

Figure 9 compares, as an example, three series of tests run at high boost pressure $(1550 \mathrm{mbar})$ and intake temperature $\left(75^{\circ} \mathrm{C}\right)$. However, similar correlations can be obtained comparing tests run at different intake pressures or temperatures. 


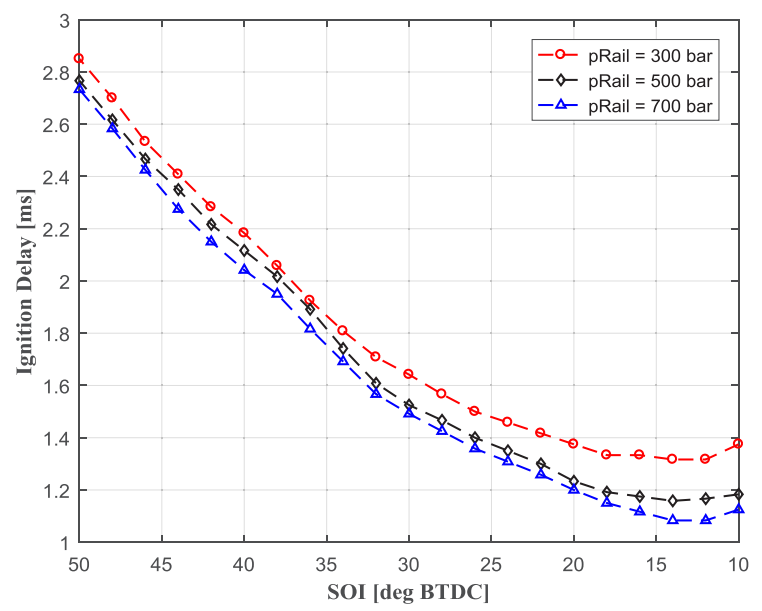

Figure 9. Comparison between the ignition delays of 3 SOI sweeps run injecting $4 \mathrm{mg} / \mathrm{stroke}$ and changing the fuel pressure (intake pressure and temperature kept at $1550 \mathrm{mbar}$ and $75^{\circ} \mathrm{C}$ respectively)

The ignition delay deviations measured when the injection pressure is varied seems to be correlated with the variations of the vaporization process, i.e. to the different duration of this stage and the different air-fuel mixing obtained. As a matter of fact, a strong correlation between ignition delay and the minimum value of $R O H R_{g}$, measured as shown in Figure 7, can be set up. The correlations obtained for all the tests run at high boost pressure (1550 mbar) and temperature $\left(75^{\circ} \mathrm{C}\right)$ have been summarized in Figure 10.

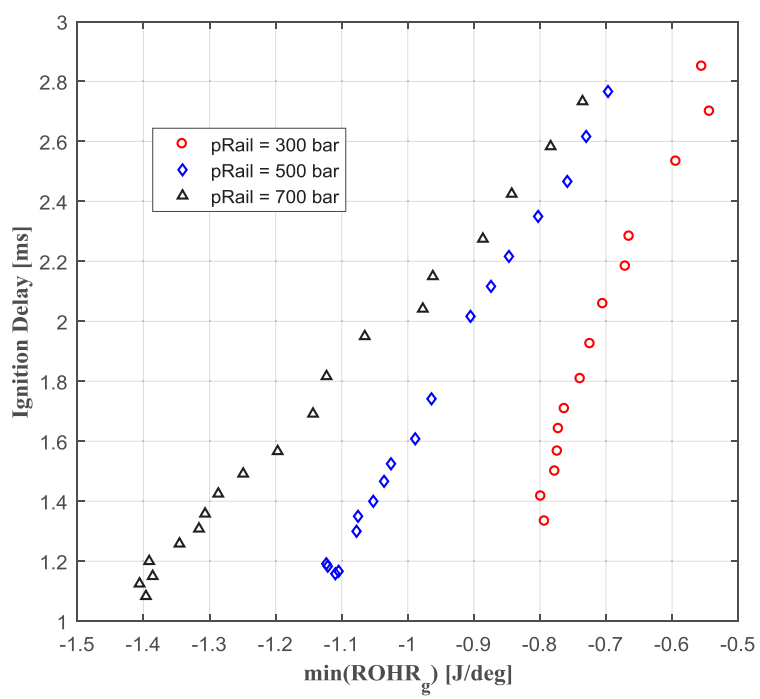

Figure 10. Ignition delay vs minimum value of the gross ROHR for $3 \mathrm{SO}$ sweeps run injecting $4 \mathrm{mg} /$ stroke and changing the fuel pressure (intake pressure and temperature kept at $1550 \mathrm{mbar}$ and $75^{\circ} \mathrm{C}$ respectively)

All the results discussed in this work provide information about the ignition mechanisms of small amounts of gasoline directly injected in a compression ignited engine. The study is the first step of a wider research activity, currently in progress, aimed at the conversion of the engine under investigation from CDC to PPC operation (with 4 cylinders fueled with gasoline) and the development of an optimal closed-loop combustion control strategy suitable to minimize the emissions and maximize the efficiency.

Page 7 of 8

\section{Conclusions and Future Work}

This work analyzes the ignition mechanisms and the combustion process of small gasoline quantities directly injected in a compression ignited engine (gasoline PPC operation). To run the engine in PPC mode, the authors developed an additional high-pressure fuel system and one additional control system to manage gasoline injection.

Different levels of boost pressure, intake temperature and rail pressure have been investigated, the goal being to point out the main effects on gasoline auto-ignition mechanisms. The analysis of heat release highlights how intake conditions, fuel pressure and injection timing affect fuel vaporization, combustion process and ignition delay. As expected, the reduction of both intake pressure and temperature increases the ignition delay, while the increase of the injection pressure accelerates the vaporization stage and consequently reduces the ignition delay.

Starting from the analyzed set of data, further investigations are being performed now to set up an optimal ignition delay model, useful to control the combustion phasing when the engine operates in PPC mode with a multiple injection strategy. In addition, the current layout is being modified to run all the 4 cylinders with gasoline. This modification requires the installation of an external boosting system, suitable to immediately increase the motored cylinder pressure during the engine fire up (i.e. when the standard turbocharging system is not yet working). The simultaneous use of a 4-cylinder layout fully operated with gasoline also overcomes some limitations characteristic of the layout used in this work, such as the study of the effects of the external EGR on the ignition process (that might affect the ignition delay mainly because of its impact on the charge temperature) or the measurement of pollutant emissions (not possible with the discussed layout because, in both cases, also the exhaust gases coming from the 3 cylinders fueled with Diesel would be used).

\section{References}

1. Torregrosa, A.J.; Broatch Jacobi, J.A.; García Martínez, A.; Monico Muñoz, L.F. (2013). "Sensitivity of combustion noise and NOx and soot emissions to pilot injection in PCCI Diesel engines," Applied Energy. 104:149-157. https://doi.org/10.1016/j.apenergy.2012.11.040.

2. Kolbeck, A.F., "Closed Loop Combustion Control - Enabler of Future Refined Engine Performance Regarding Power, Efficiency, Emissions \& NVH under Stringent Governmental Regulations", SAE Technical Paper 2011-24-0171, 2011, https://doi.org/10.4271/2011-24-0171.

3. Curran, S., Hanson, R., Wagner, R., and Reitz, R., "Efficiency and Emissions Mapping of RCCI in a Light-Duty Diesel Engine," SAE Technical Paper 2013-01-0289, 2013, https://doi.org/10.4271/2013-01-0289.

4. Wissink, M. and Reitz, R., "Direct Dual Fuel Stratification, a Path to Combine the Benefits of RCCI and PPC," SAE Int. J. Engines 8(2):878-889, 2015, https://doi.org/10.4271/2015-010856.

5. Li, C., Xu, L., Bai, X.-S., Tunestal, P. et al., "Effect of Piston Geometry on Stratification Formation in the Transition from HCCI to PPC," SAE Technical Paper 2018-01-1800, 2018, https://doi.org/10.4271/2018-01-1800.

6. Dempsey, A. B., Curran, S. J., \& Wagner, R. M. (2016). A perspective on the range of gasoline compression ignition combustion strategies for high engine efficiency and low NOx and soot emissions: Effects of in-cylinder fuel stratification. 
International Journal of Engine Research, 17(8), 897-917. https://doi.org/10.1177/1468087415621805.

7. Kimura, S., Aoki, O., Kitahara, Y., and Aiyoshizawa, E., "UltraClean Combustion Technology Combining a Low-Temperature and Premixed Combustion Concept for Meeting Future Emission Standards," SAE Technical Paper 2001-01-0200, 2001, https://doi.org/ 4271/2001-01-0200.

8. Belgiorno, G., Dimitrakopoulos, N., Di Blasio, G., Beatrice, C., Tunestål, P., Tunér, M., "Effect of the engine calibration parameters on gasoline partially premixed combustion performance and emissions compared to conventional diesel combustion in a light-duty Euro 6 engine", Applied Energy, Volume 228, 2018, Pages 2221-2234, ISSN 0306-2619, https://doi.org/10.1016/j.apenergy.2018.07.098.

9. Belgiorno, G., Dimitrakopoulos, N., Di Blasio, G., Beatrice, C. et al., "Parametric Analysis of the Effect of Pilot Quantity, Combustion Phasing and EGR on Efficiencies of a Gasoline PPC Light-Duty Engine," SAE Technical Paper 2017-24-0084, 2017, https://doi.org/10.4271/2017-24-0084.

10. Leermakers, C., Somers, L., and Johansson, B., "Combustion Phasing Controllability with Dual Fuel Injection Timings," SAE Technical Paper 2012-01-1575, 2012, https://doi.org/10.4271/2012-01-1575.

11. Ravaglioli, V., Ponti, F., De Cesare, M., Stola, F. et al., "Combustion Indexes for Innovative Combustion Control," SAE Int. J. Engines 10(5):2371-2381, 2017, https://doi.org/10.4271/2017-24-0079.

12. Masurier, J., Waqas, M., Sarathy, M., and Johansson, B., "Autoignition of Isooctane beyond RON and MON Conditions," SAE Int. J. Fuels Lubr. 11(4):459-468, 2018 , https://doi.org/10.4271/2018-01-1254.

13. Gentz, G., Dernotte, J., Ji, C., and Dec, J. "Spark Assist for CA50 Control and Improved Robustness in a Premixed LTGC Engine Effects of Equivalence Ratio and Intake Boost," SAE Technical Paper 2018-01-1252, 2018, https://doi.org/10.4271/2018-01-1252.

14. An, Y., Mubarak Ali, M.J., Vallinayagam, R., AlRamadan, A. et al., "Compression Ignition of Low Octane Gasoline under Partially Premixed Combustion Mode," SAE Technical Paper 2018-01-1797, 2018, https://doi.org/10.4271/2018-01-1797.

15. Matsuura, K. and Iida, N., "Effect of Temperature-Pressure Time History on Auto-Ignition Delay of Air-Fuel Mixture," SAE Technical Paper 2018-01-1799, 2018, https://doi.org/10.4271/2018-01-1799.

16. Buri, S., Kubach, H., \& Spicher, U. (2010). "Effects of increased injection pressures of up to $1000 \mathrm{bar}$ - opportunities in stratified operation in a direct-injection spark-ignition engine". International Journal of Engine Research, 11(6), 473-484. https://doi.org/10.1243/14680874JER608.

17. Leermakers, C., Bakker, P., Somers, L., de Goey, L. et al., "Butanol-Diesel Blends for Partially Premixed

Combustion," SAE Int. J. Fuels Lubr. 6(1):217-229, 2013, https://doi.org/10.4271/2013-01-1683.

18. Medina, M., Fatouraie, M., and Wooldridge, M., "High-Speed Imaging Studies of Gasoline Fuel Sprays at Fuel Injection Pressures from 300 to 1500 bar," SAE Technical Paper 2018-010294, 2018, https://doi.org/10.4271/2018-01-0294.

19. Ravaglioli V., Ponti F., Carra F., De Cesare M., "Heat Release Experimental Analysis for RCCI Combustion Optimization". ASME Internal Combustion Engine Division Fall Technical Conference, https://doi.org/10.1115/ICEF2018-9714.

20. Heywood, John B. Internal Combustion Engine Fundamentals. New York: McGraw-Hill, 1988.

\section{Contact Information}

Federico Stola

federico.stola@magnetimarelli.com

\section{Definitions/Abbreviations}

ICE

RCP

PPC

CDC

CI

VGT

HCCI

EGR

ROHR

$\operatorname{ROHR}_{g}$

pRail

SOI

ET

SOC

DSOI

DET

$\gamma$

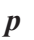

V

TDC

BTDC
Internal combustion engine

Rapid control prototyping

Partially premixed combustion

Conventional diesel combustion

Compression Ignition

Variable geometry turbine

Homogeneous charge compression ignition

Exhaust gas recirculation

Rate of heat released

Gross rate of heat release

Gasoline injection pressure

Start of injection (gasoline)

Energizing time (gasoline)

Start of combustion

Diesel start of injection

Diesel energizing time

Specific heat ratio

In-cylinder pressure

In-cylinder volume

Crankshaft angle

Top dead center

Before top dead center

Page 8 of 8 